\title{
Texto sonso, ou a base diagramática da arquitetura contemporânea ${ }^{a}$
}

\author{
Robert E. Somol
}

a. Dummy text, or The Diagrammatic Basis of Contemporary Architecture. Somol, Robert E. Introdução, in Eisenman, Peter, Diagram Diaries, New York: Universe Publishing, 1999, pp.6-25. Segundo o dicionário Webster, dummy, em inglês, pode ser bobo, tolo ou dissimulado, sonso, ou até mesmo mudo. A palavra tem sido muito utilizada para qualificar livros de toda a ordem, sobre os mais diversos assuntos, qualificados como for dummies, para bobos, livros que qualquer um pode entender, de modo fácil. Pode ser a intenção de Somol, com seu ensaio, clarificar questões sobre o diagrama para que qualquer um possa compreender. Mas pode haver um segundo sentido, de dissimulado, algo escondido, disfarçado, ao mesmo tempo que esperto, perspicaz. Como Guimarães Rosa, poder-se-ia, nesse caso, utilizar 'sonsagato', vocábulo que contém a dissimulação de sonso e a sagacidade do gato [Cf. O léxico de Guimarães Rosa, Martins, N.S., São Paulo: Edusp, 2001, p.466]. Assim, numa acepção menos elaborada, optou-se por traduzir dummy por sonso, pretendendo abranger esse último sentido, como em Rosa. (N.E: as notas indicadas por letras correspondem às observações do tradutor. Já as indicadas por números, que estão no final do texto, correspondem às notas originais do texto de Robert E. Somol).

b. A tese de Eisenman foi recentemente publicada por uma editora Suíça. The Formal Basis of Modern Architetcture, Baden: Lars Mueller Publishers, 2006 eter Eisenman afirma, com freqüência, que sua tese de doutorado, de 1963, "As bases formais da arquitetura moderna"b, foi uma resposta crítica à tese de Christopher Alexander, desenvolvida pouco antes em Cambridge e que seria publicada como "Notas sobre a síntese da forma"1. O prospecto arquitetural desses projetos não poderia ser mais antagônico - determinar a forma a partir de um bloco teórico versus permitir que a potencialidade da forma indique as forças de sua própria emergência -, mas não se deve esquecer que as técnicas do diagrama são centrais para os dois. De fato, Alexander inicia o prefácio de suas Notas, na edição de 1971, afirmando, enfaticamente, que a contribuição mais significativa de seu livro é "a idéia do diagrama". De algum modo, a presente coletânea, Diagram Diaries, desenvolve uma asserção correlata, como um prefácio a posteriori, para uma dissertação não publicada que, entretanto, agora se dirige a (e é demonstrada pela) obra de uma carreira repleta de trabalhos que provocam interferências.

De modo geral, até onde se pode observar, a técnica e o procedimento fundamental do conhecimento arquitetônico mudaram, ao longo da segunda metade do século XX, do desenho para o diagrama. Isto não é uma sugestão de que diagramas, de um modo ou de outro, não tenham sempre sido constitutivos da arquitetura em vários períodos de sua história, mas, simplesmente, que apenas nos últimos trinta e poucos anos o diagrama foi totalmente "atualizado", se tornando, quase inteiramente, o problema da arquitetura. Procedendo por sobressaltos através de obsessões seriadas com a forma, a linguagem e a representação - contudo, como se verá, também com o programa, as restrições e o desempenho - o diagrama parece que emergiu como ferramenta definitiva para o discurso e a produção da arquitetura, tanto em seus aspectos milenares, como nos extremos radicais. Relativamente impermeável à promoção de ideologias, o diagrama instigou uma gama de práticas contemporâneas. Assim como Robert Venturi, que resumiu o efeito de sua dissertação de mestrado, em 1950, como "um grande diagrama", Lawrence Halprin publicou um livro de diagramas, em 1970 - ao que se refere como "pontuações" - pretendendo delinear os fundamentos de uma renovada disciplina do design. Significativamente, até a crítica de Klaus Herdegc ao diagrama pedagógico e projetivo, de inspiração bauhausiana, procedeu, simplesmente, por um modo alternativo de análise diagramática.

Não surpreende que, nesse momento, o discurso sobre o diagrama tivesse se tornado tão confuso dado ao seu, quase universal, uso e abuso e a sua simultânea promoção e denegação. Não se pode dizer o mesmo do traço de identidade anterior da disciplina, o ato de desenhar, que, segundo Reyner Banham "teve um valor tão crucial para os arquitetos que, ser incapaz de pensar sem desenhar, se tornou sua verdadeira marca, largamente socializada na profissão da arquitetura." 2 Depois da guerrad, com a crescente inabilidade para articular, convincentemente, as ambições formais e funcionais do modernismo, as primeiras aparições do diagrama se solidificam em torno de dois eixos possíveis, que Colin Rowe depois identificaria como "paradigma" (que abarca ideais a priori) e "programa" (demanda empírica da realidade). Rowe, significativamente, ressalta que as duas posições "nos condenam a nada mais que simples repetição", mas, por fim, pende para o lado do paradigma (ou tipo) e sugere que, fiel à sua 


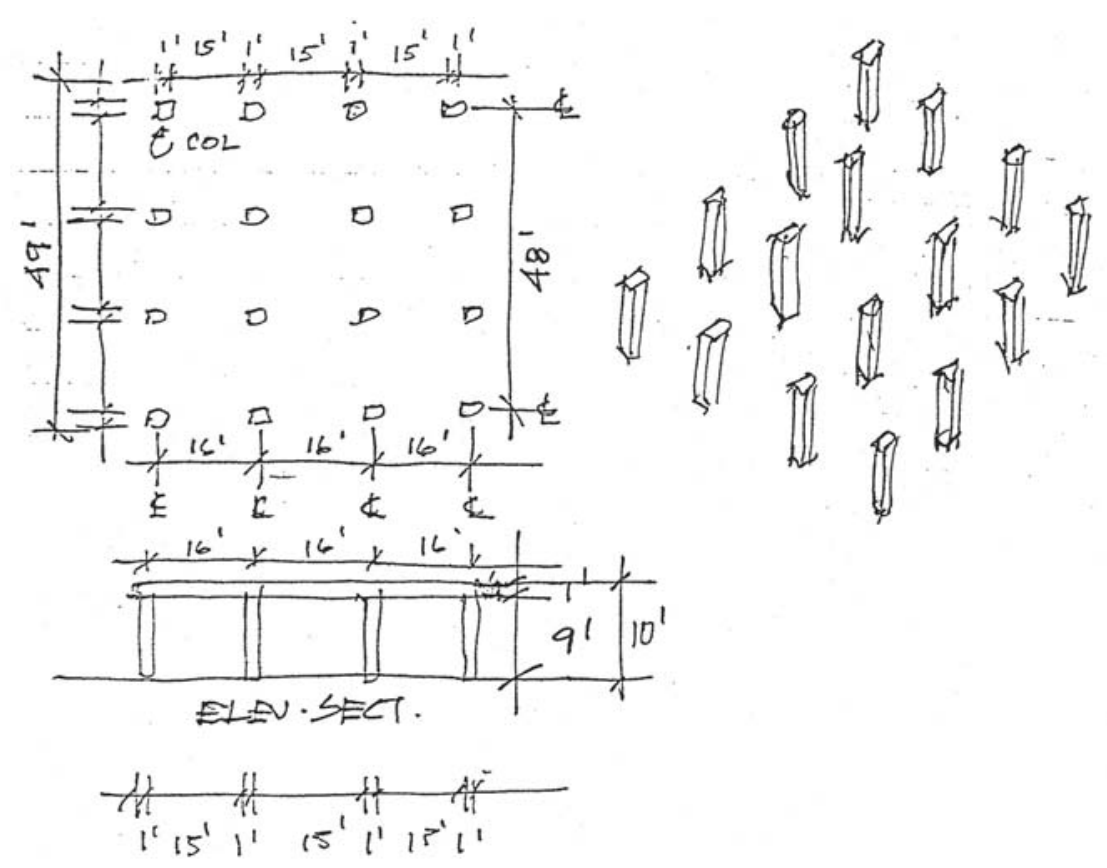

Figura 1: O diagrama dos nove-quadrados, segundo Hejduk. Fonte:

c. Trata-se do livro The Decorated Diagram: Harvard Architecture and the Failure of the Bauhaus Legacy [Cambridge: MIT Press, 1985], de Klaus Herdeg, publicado nos anos 80 . Herdeg era, então, professor na Escola de Arquitetura da Universidade Columbia (Nova lorque) e criticou duramente os métodos de ensino de projeto aplicados na Escola de Arquitetura de Harvard (Cambridge) que, no pósguerra, teve Gropius como diretor.

d. Trata-se, como em todo o ensaio, de referência à Segunda Grande Guerra (193945) e ao referente segundo pós-guerra.

e. Billding, jogo de palavras entre building (edifício) e billboard (painel de avisos, de anúncios). Para uma descrição e imagens do projeto de Venturi, ver: http:// www.vsba.com/projects/ fla_archive/55.html. predileção pelo humanismo renascentista, precisamente o desenho irá sobrepujar as alternativas diagramáticas que, ele mesmo, tão habilmente, identificou para tão rapidamente negar. ${ }^{3}$ Mais recentemente, contudo, no lugar de um retorno ao desenho e a tipos modificados, uma versão alternativa de repetição (um modo potencialmente não-linear de repetição) tem sido procurada ao se repensar e estender a lógica do diagrama. Assim, o surgimento do diagrama, um procedimento mais polêmico que o desenho, acompanha a falência do consenso pós-renascentista acerca do papel do arquiteto e atinge sua apoteose com a emergência dos "arquitetos da informação" (ou arquitetoscríticos) depois de 1960. Esta última associação é uma primeira sugestão de que nem todos os recentes usos do diagrama são igualmente diagramáticos.

Como procedimento dominante nas práticas híbridas dos arquitetos-críticos da neo-vanguarda, esse uso específico do diagrama promete elidir a oposição entre físico-forma e moral-palavra, feita por Rowe no pós-guerra. Se por um lado Rowe iria promover o primeiro par sobre o segundo, em sua tentativa de estender o legado do modernismo (em contraste com seu alter ego, Banham, que elaboraria as implicações do segundo par), os arquitetos da neo-vanguarda são impelidos para o diagrama por que - diferente do desenho, o partido, ou do texto, o fluxograma do programa de necessidades - ele aparece como a primeira instância a operar precisamente entre a forma e a palavra. Para os intentos dessa breve introdução, essa atitude frente ao diagrama tem inúmeras implicações: o fato de ser, fundamentalmente, um dispositivo disciplinar, da disciplina, que se situa sobre e desfaz oposições institucionais e discursivas (que provê a disciplina de um caráter projetivo para novas abordagens); que sugere um modo alternativo de repetição (que se desvia das obras das vanguardas modernas e vislumbra a repetição como produção da diferença, mais do que como produção da identidade); e que é um dispositivo de execução mais do que de representação (isto é, uma ferramenta do virtual mais do que do real). Para uma versão prévia desse novo papel disciplinar inscrito no projeto, é possível ver, por exemplo, o projeto de Robert Venturi para o concurso do National Football Hall of Fame (também chamado Billdingboard, de 1967)e, que consiste num painel tripartido como fachada de entrada, uma cobertura em arco do espaço de exposições e uma arquibancada em plano inclinado ao fundo. O que 
f. Apesar do caráter experimental, exploratório e especulativo da série de projetos de Wall Houses, em 2001, a cidade de Groening, na Holanda, construiu a Wall House 2. Há dois sites com i m a ge n s: [ h t t p : // www.ivarhagendoorn.com/ photos/architecture/ wall_house.html]; [http:// www.figure-ground.com/travel/image.php?wallhouse].

g. A compreensão do significado da palavra design, na língua portuguesa, é bastante confusa, uma vez que se mistura com a idéia de desenho, ainda mais por que desenho pode também significar projeto. Em língua inglesa, há distinção entre desenho (drawing) e design (manifestação material da cultura). Para uma discussão abrangente, ver FERRARA, Lucrécia D'Aléssio, "Do Desenho ao Design: um percurso semiótico?", in Galáxia n7, abril de 2004, pp.19-48 [http://www.pucsp.br/pos/ cos/galaxia/num 07 / index.htm] e Diálogo (vários autores) "Espaço, design, cultura", in Galáxia n6, outubro de 2003, pp.191-209 [http://www. pucsp.br/pos/ cos/galaxia/num06/ index.htm]. se vê em corte - desde a arquibancada levemente inclinada, olhando transversalmente ao arco da cobertura, em direção a armadura da fachada frontal é a rotação em 90 graus de uma superfície horizontal (um tampo de mesa ou prancheta) transformada em objeto vertical. Como nas Wall Houses ${ }^{\dagger}$ de John Hejduk, o projeto de Venturi descreve a transformação do espaço horizontal da escrita em uma superfície vertical do visual, da imagem, a moralpalavra de Rowe se tornando físico-matéria, um processo que diagrama uma nova identificação profissional, que unifica palavra e design ${ }^{9} .{ }^{4} \mathrm{~A}$ apropriação, por Venturi, deste tampo de mesa reclinável - um instrumento do escritório de arquitetura que evidencia o estatuto documental da disciplina - resgata o uso similar de ready-mades industriais por Corbusier (por exemplo, arquivos de gaveta, suportes de garrafa, navios a vapor, tubulações de exaustão [tipo cachimbo], etc.) como base para novos sistemas organizadores nas Unidades de Habitação e outros projetos. A prancheta em si (e aqui Venturi se refere à elevação frontal como 'um cavalete alto') passou a ser usada como diagrama que mobiliza uma série de relações e forças. Além disso, procedendo a partir de uma releitura enviesada da disposição proto-maquínica ou diagramática de Corbusier, esse projeto também sugere a existência de um modo alternativo de repetição em arquitetura, que seja distinto daquele e oposto às reconstruções funcionais e formais do modernismo pós-guerra.

A história da produção arquitetônica, nos últimos quarenta anos, pode ser amplamente caracterizada como um desejo de estabelecer a arquitetura como autônoma e heterogênea, em contraste ao edifício anônimo e homogêneo associado à retórica do entre guerras e da experiência modernista do pósguerra. Essa busca por autonomia e heterogeneidade - que convoca sua fundamental antinomia, o par identidade e multiplicidade - tomou várias formas nesse período, uma das quais, a contínua releitura ou repetição da vanguarda modernista, embora agora no contexto extremamente transformado do pós-guerra. Em resumo, pode ser útil distinguir dois tipos de repetição, uma associada ao historicismo pós-moderno e outra associada às premissas construtivas, ou releituras, da neovanguarda. O primeiro modo de repetição pode ser identificado por ícones, semelhanças e cópias, enquanto o segundo está alinhado com simulacros e indícios. ${ }^{5} \mathrm{O}$ primeiro se baseia nos ideais de um modelo ou numa origem, como uma economia de identidade e pode ser pensado como tipologicamente direcionado (imitação vertical, com precedentes imemoriais). Em contraste, o segundo coloca em movimento séries divergentes e se dá como um processo contínuo de diferenciação. Um aponta retroativamente para um momento estático da existência, ou outro avança através de possíveis modos do porvir. Mais uma vez, isso tem relação direta com a distinção feita por Gilles Deleuze entre factício (ou artificial) e simulacro:

"É no coração da modernidade, no ponto em que o modernismo assenta seus valores, que o factício e o simulacro se opõem como dois modos de destruição: os dois niilismos. Entre a destruição que conserva e perpetua a ordem estabelecida das representações, modelos e cópias e a destruição de modelos e cópias que constrói um caos criativo, há uma grande diferença; este caos, que coloca em movimento simulacros e desperta um fantasma, é a mais inocente de todas as destruições, aquela do Platonismo." 6

Agora é possível diferenciar a repetição da neovanguarda (aquela do simulacro) da larga trajetória dos historicismo pós-moderno, que idealiza a obra, estabiliza o referente e sustenta a semelhança. Nesse ponto, o historicismo tem pouco a ver com estilo, sendo mais um modelo de operação, uma vez que a obra historicista pode incluir o moderno, como se vê nos projetos de Richard Meier. Um tipo particular de repetição está no coração da modernidade - a releitura das vanguardas - e é esta prática que se baseia no diagrama em seu sentido mais pleno. Finalmente, a distinção entre modelos de repetição oferece visões contraditórias também sobre autonomia - isto é, há a autonomia disciplinar, baseada na tipologia e há o modo alternativo, associado à neo-vanguarda, que entende autonomia como processo de auto-geração ou autoorganização, um modelo que permite a emergência e a transformação formal-material sem a intervenção autoral, em que o tempo é um elemento ativo ao invés de passivo.

Já em sua tese, Eisenman sublinhava que os diagramas de Rowe e Alexander (que são mais preci- 
h. Para uma discussão mais extensa sobre esses aspectos e ainda mais aprofundada sobre o diagrama e sua relação com as tecnologias digitais na arquitetura, ver LACOMBE, Octavio. Diagramas Digitais: pensamento e gênese da arquitetura mediada por tecnologias numéricas, Tese de Doutorado, São Paulo: FAUUSP, 2006.

i. Originalmente publicado em 1949. WITTKOWER, Rudolph. La arquitetctura em la edad del humanismo. Há uma edição argentina: Buenos Aires: Nueva Visión, 1958; outra espanhola: Madrid: Alianza Editorial, 1995.

j. O New York Five (os Cinco de Nova lorque) era formado por Peter Eisenman, John Hejduk, Michael Graves, Charles Gwathmey e Richard Meier. Teve como mentor Philip Johnson, que agrupou os cinco arquitetos mais por motivos acadêmicos do que por motivações de projeto. Apareceram pela primeira vez sob essa designação em exposição promovida por Arthur Drexler, no Museu de Arte Moderna de Nova lorque, em 1967. Em 1972, foi publicado o livro, com a introdução de Rowe. EISENMAN, Peter et al.. Five Architects. Nova Iorque: Oxford University Press, 1972 samente 'paradigmas' e 'padrões', respectivamente) não eram suficientemente diagramáticos, uma vez que tentavam representar ou identificar uma verdade congelada (se formal ou operacional seria irrelevante). Desenvolvendo o potencial para registrar as forças e os movimentos do contexto através de inflexões sobre uma forma genérica, o diagrama transformacional de Eisenman antecipa a necessidade (e prevê as possibilidades) do posterior desenvolvimento de softwares de modelamento 3D e animação. ${ }^{h}$ Mesmo nessa nascente construção dinâmica do diagrama (e modelo de repetição não-linear), Eisenman imaginou que a malha [ou grid] poderia mudar de ferramenta analítica para a descrição - a infra-estrutura invisível do formalismo do pós-guerra - para material a ser manipulado por si só. Claro, esta abordagem está em direta oposição com a de Rowe, que elimina o elemento selvagem do tempo, em favor da semelhança imemorial, da segurança do substrato estabilizador da malha ideal.

O primeiro ensaio publicado por Rowe é virtuoso no criticismo formal da arquitetura. Oferece a sutil comparação e diferenciação entre a Villa Garches, de Corbusier e a Villa Malcontenta, de Palladio, análise que permanece notável e irresoluta ainda hoje, quase cinqüenta anos depois de sua aparição original. Certamente que se pode perceber, em Rowe, a influência da análise geométrica das vilas de Palladio realizada por Wittkower, trabalho que atingiria sua forma definitiva em Architectural Principles in the Age of Humanism ', publicado dois anos depois do ensaio de Rowe. De todo modo, a permanência da contribuição de Rowe, independente de qualquer outro entendimento, está em ter cruzado períodos históricos e ter localizado um projeto maneirista-humanista no centro do movimento moderno, além de ter estabelecido o arcabouço discursivo através do qual as polêmicas da arquitetura têm sido projetadas desde então - um ato que pode ser descrito como um desvio ideológico audacioso. Além disso, até mesmo naquele momento tão anterior, o ponto principal girava em torno da propriedade ou da apropriação da "repetição", como sugerem as duas últimas linhas do ensaio:

"A vila neo-palladiana, na melhor das hipóteses, se torna um objeto pitoresco nos parques Ingleses e Le Corbusier se tornou a fonte para inúmeros pastiches e tediosas exibições de virtuosismo técnico; mas a magnífica qualidade realizada nos originais raramente pode ser encontrada nas obras de neopalladianos ou em expoentes do "estilo Corbu". Essas distinções requerem pouca diligência; e, sem dúvida, só deveriam, sentenciosamente, sugerir que, no caso de obras derivativas, a aderência às regras é que talvez tenha falhado."7

Embora Rowe pareça estar distinguindo entre duas formas de repetição - uma vez que a repetição entre Palladio e Corbusier é aparentemente endossada - o modelo que defende continua fundamentado no ideal dos "originais". Mais significativa, talvez, seja sua alusão ao terreno legal, a "aderência às regras" para julgar casos de repetição, a primeira das muitas invocações à regra da lei na sua reconstrução liberal do modernismo. Mais ainda, mesmo crítico da versão do "estilo Corbu" do imediato pós-guerra, vinte e sete anos depois, Rowe escreveria uma apresentação dos New York Five defendendo a repetição de Le Corbusier, ainda que fosse, como ele mesmo confessou, "uma introdução amplamente negativa - um contraataque a um ataque potencial", um exemplar primitivo da lógica lúbrico-enviesada, costurada com a única intenção de promover seus clientes: "Nos termos de uma teoria geral do pluralismo, como imputar quaisquer faltas ao princípio?" ${ }^{8}$ E se Palladio e Corbusier se equacionam, como na análise de Rowe, então é lógico que ele ressalte demonstrando, de mais de uma maneira, sua obsessão pelo pensamento analógico - que os Five "se colocam no mesmo papel, secundário, de Scamozzi frente a Palladio".

No mesmo ano em que elaborou sua defesa, de certa forma relutante, dos New York Five, Rowe escreveu um adendo para seu ensaio "Mathematics" que clareava sua posição sobre a repetição. Aqui, ele descreve seu criticismo como "Wolfliniano de origem" e diz que "começa com configurações aproximadas e...então avança para identificar diferenças. " ${ }^{9}$ Esta abordagem deriva do sentido descrito anteriormente, aquele que Deleuze associa com o axioma "só o que é parecido se diferencia". Esse modo de identificar diferenças se baseia numa linguagem existente, ou numa armadura ideal, contra a qual instâncias 
k. Trata-se de dois dos ensaios em Mathematics of the Ideal Villa: Chicago Frame e Transparency: Literal and Phenomenal, este último escrito com Robert Slutzky. Para este, há uma tradução em português: ROWE, Colin e SLUTZKY, Robert. Transparência literal e fenomenal, tradução Leila Vasconcellos, in Gávea, $n^{\circ} 2$, pp. 33-50. Rio de Janeiro: PUC RJ, 1985. Para os outros ensaios, há tradução em espanhol: ROWE, Collin. "Las matemáticas de la vivienda ideal", in Manierismo y arquitectura moderna y otros ensayos. Barcelona, GG, 1978

I. Para mais detalhes sobre o diagrama dos nove-quadrados utilizado por Hejduk, ver: HEJDUK, John. The mask of Medusa, works 1947-1983. New York: Rizzoli, 1985, pp.37-38.

$m$. Em seu livro Princípios da Arquitetura na Idade do Humanismo, Wittkower analisa 11 vilas de Palladio, apresentando seus respectivos diagramas. Um décimo-segundo diagrama é apresentado como síntese das configurações estudadas. Essa seriia a "décima-segunda vila", segundo Somol.

n. Referência à leitura crítica do espaço urbano realizada por Rowe, publicada em livro com o título Collage City. Há tradução espanhola: Rowe, C. E Koetter, F. Ciudad Colage, Barcelona: Gustavo Gili, 1981.

o. Harold Bloom, crítico literário norte-americano, publicou The Anxiety of influence: a theory of poetry, [Oxford University Press, 1973]. Bloom defende que há uma sincronicidade na poesia, em que cada poeta contribui para a evolução da poesia, pois cada poema é uma resposta a toda a história acumulada da poesia. Não há poesia ou poeta que não seja influenciado por toda a história pregressa da própria arte. O livro é considerado um dos mais importantes dos últimos 20 anos e Bloom um dos mais conceituados críticos de literatura.

p. Vladivostok é o segundo livro da trilogia que publica os projetos exploratórios e experimentais de Hejduk, composta por Mask of Medusa [NY: Rizzoli, 1985], Vladivostok, Breath of Bacchus [NY: Rizzoli, 1989] e Soundings: a work [NY: Rizzoli, 1993]. aparentemente disparatadas como Garches e Malcontenta, podem ser relacionadas e diferenciadas - a ênfase na dispersão, em Corbusier e na centralidade, em Palladio, podem ser definidas como opções viáveis e coerentes no bojo de um paradigma mais amplo - e pelo qual as cópias mal feitas podem ser descartadas, por estarem muito distantes do modelo apropriado.

Uma extensão desse modelo de repetição como projeto pedagógico - que encontra largo suporte intelectual nos ensaios "Chicago Frame" e "Transparency" k - seria oficialmente instituído em 1954, na Universidade do Texas em Austin, com um memorando para o diretor Harwell Hamilton Harris, escrito em pseudônimo por Rowe e Bernard Hoesli. ${ }^{10}$ E foi a partir dessa estrutura curricular que, inicialmente nas aulas de John Hejduk, o problema dos nove-quadrados ' emergiria talvez como o mais duradouro e disseminado problema inicial de projeto no período do pós-guerra. ${ }^{11} \mathrm{~A}$ elegância e a ingenuidade desse problema se assentam no modo como consolida uma série de discursos e proposições. Se os pré-requisitos técnicos que permitiriam à arquitetura moderna renovarse, exclusivamente sobre a base estrutura e espaço, existiam por quase cem anos, as fontes estética, filosófica e intelectual - isto é, a combinação singular entre cubismo, liberalismo, psicologia gestalt e novo criticismo, com uma compreensão renovada das organizadoras geometrias maneiristas - não estariam consolidadas como conjunto articulado até os anos cinqüenta, oferecendo um novo fundamento disciplinar alto-moderno, ou modernomaneirista, para o projeto e a pedagogia arquitetural. Como dispositivo educacional, o diagrama dos nove-quadrados emerge da fusão de dois diagramas modernos - o Dominó de Corbusier (estrutura) com a axonométrica de van Doesburg (espaço) - filtrados pela redutiva lógica planimétrica substanciada por Wittkower na "décimasegunda vila"m de Palladio. O que esse problema forneceu foi disciplina para a arquitetura moderna, um argumento perspicaz e perverso da faculdade retórica contra aqueles que poderiam entender a arquitetura como, simplesmente, a adição literal de sistemas construtivos e requisitos programáticos. Além disso, esse diagrama assume uma linguagem da arquitetura fundada sobre a articulação de uma série de dialéticas (centro e periferia, vertical e horizontal, dentro e fora, frontalidade e rotação, sólido e vazio, ponto e plano, etc.), uma lógica da contradição e da ambigüidade. E é, em grande parte, para as lições vindas do cubismo analítico e sintético (e dos modelos compositivos da colagem que emanam do segundo) que Rowe prossegue retornando, em seu aporte pictórico da linguagem da arquitetura moderna, um viés ótico presente até mesmo em suas considerações sobre o trabalho dos Five:

"Seria mais razoável e mais modesto reconhecer que, nos anos inaugurais desse século, grande revoluções no pensamento ocorreram, resultando em profundas descobertas visuais, que ainda permanecem inexplicadas e que, ao invés de assumir a mudança intrínseca como prerrogativa para todas as gerações, seria mais proveitoso reconhecer que certas mudanças são tão enormes a ponto de impor diretivas (caminhos) que não podem ser resolvidos no tempo de uma vida. Isso diz respeito às invenções plásticas e espaciais do cubismo e a proposição que, independente do que se diga, elas possuem uma eloqüência e uma flexibilidade que ainda continuam tão estarrecedoras como foram então. "12

A flexibilidade do Cubismo e da colagem fornece a base disciplinar e institucional para a arquitetura que começa com Rowe, enquanto que as diversas séries de vilas ideais e cidades-colagem ${ }^{n}$ que derivam dessa prática, representam uma reflexão sustentada sobre a forma e o conteúdo, de arranjos individuais e coletivos, e uma investigação sobre as várias leis de composição e associação relativas ao par parte-todo.

Em seu debate para a reconstrução formalista do modernismo no pós-guerra, o sujeito da 'influência ansiosa' de Hejduk e Eisenman, para emprestar o modelo de Harold Bloom , era mais um crítico forte do que um poeta forte. Em outras palavras, toda a sua produtiva releitura dos predecessores modernistas europeus pode ser entendida como uma virada no interior e contra a produção do formalismo de Rowe, e é esta virada que permite com que eles desenvolvam outras possibilidades não elaboradas no interior da tradição. Nesse sentido, é possível ler caracteres no Vladivostok de Hejduk ${ }^{p}$ ou nos estudos tipológicos de Eisenman, em seu projeto para o concurso do Rebstockpark, com extensões perversas dos diagramas gestalt, usados 
q. Colin Rowe e Robert Slutzky escreveram dois artigos, aparentemente no mesmo ano de 1956, com o mesmo título: Transparency: Literal and Phenomenal. Entretanto, os artigos só foram publicados em 1963 e 1971. Em 1976, o segundo artigo integrou a coletânea Mathemathics of the Ideal Villa and Other Essays. Tomando como referencia o espaço construído pelo cubismo [Robert Slutzky era pintor], o ensaio é fundamental para a compreeensão das qualidades fenomenais do espaço da arquitetura moderna, a partir da leitura da Vila Garches, de Corbusier. Em um caso raro, o ensaio tem tradução para o português: ROWE, Colin e SLUTZKY, Robert. Transparência literal e fenomenal, tradução Leila Vasconcellos, in Gávea, $n^{\circ} 2$, pp. 33-50. Rio de Janeiro: PUC RJ, 1985.

r. "Galpão decorado" é a tradução de decorated shed (tinglado decorado, em espanhol), arquitetura definida por Robert Venturi, em Learning from Las Vegas [1977], como barracões que servem de estrutura, ou suporte, para sinais, letreiros, e outras formas de comunicação. Ver VENTURI, Robert., IZENOUR, Steven., SCOTT-BROWN, Denise. Aprendiendo de Las Vegas: el simbolismo olvidado de la forma arquitectónica. Barcelona: Editorial Gustavo Gili, 1978, pp. 114 e ss.

s. A crítica parece ser mais semiológica do que semiótica, uma vez que nenhum dos arquitetos ou críticos do diagrama faz menção a Charles Sanders Peirce (criador da Semiótica). Quando o fazem, fazem-no com uma abordagem dualística (como na Semiologia de Ferdinand de Saussure, um dos pilares para o posterior desenvolvimento do Estruturalismo, baseado na relação significado/ significante) e não triádica, como na semiótica. É o caso do ensaio Semiótica e Arquitetura [1973], de Diane Agrest e Mario Gandelsonas, que foi recentemente vertido para o português, em NESBITT, Kate (org.), Uma Nova Agenda para a Arquitetura - antologia teórica (1965-1995), tradução Vera Pereira, São Paulo: Cosac \& Naify, 2006. O próprio Eisenman, no posfácio do li- por Rowe e Slutzky, em seu segundo artigo acerca da transparência de 1956 ` . Contudo, mesmo se apoiando nas fontes de Rowe, os projetos de Hejduk e Eisenman subvertem, simultaneamente, os valores de transparência, verticalidade, visualidade e a definição de figura e fundo para as quais o diagrama foi inicialmente invocado para suportar.

Se no diagrama dos nove-quadrados, a separação entre espaço e estrutura favorece a articulação de relações plástico-formais, a desconexão entre signo e caixa no "galpão decorado" 29 de Venturi sugere, basicamente, que essas manipulações são desnecessárias, uma vez que todas as relações serão consumidas pelo ruído da superfície.

Enquanto Rowe e companhia tentavam recolocar a concepção moderna de espaço neutro e homogêneo com a figuração positiva da forma, a neovanguarda começou a questionar a estabilidade da forma ao compreendê-la como uma construção ficcional, um signo. Essa crítica semióticas registraria que a forma não é meramente um fenômeno visual, neutro, mas construído por relações lingüísticas e institucionais. Apontando para múltiplas direções, este programa apareceu, pela primeira vez, nos desdobramentos da prática particular de colagens de Venturi que não eram meramente compositivas, mas que incluiriam tanto textos como referências básicas (representações icônicas específicas). Subsequentemente, o desvio da forma de Eisenman não se moveria em direção a informação e ao signo (como fez Venturi), mas para o traço, o vestígio, o índice perdido no processo formal (estressando, assim, ausência e conceito). Ao mesmo tempo, Hejduk investigaria a construção teatral da forma, através de relações e instruções altamente orquestradas, tanto lingüísticas como contratuais (isto é, simbólicas). Assim, esse tripé crítico iria variar o primeiro plano do contexto (os mecanismos de arranjo exteriores a forma); o processo (os procedimentos efetivos na formação); e o hábito (a relação da forma com o sujeito). Com a neo-vanguarda, então, a forma seria, precisamente, sujeitada por funções de seus descendentes lingüísticos: informação, transformação, e performance.

De sua parte, Eisenman desenvolveu uma de suas primeiras e mais extensas análises da forma ao reescrever duas estruturas do italiano Giuseppe
Terragni - a Casa del Fascio e a Casa Giuliani-Frigerio ${ }^{\dagger}$ - quando encontrou estas obras ao viajar a Como com Rowe, no verão de 1961. Antes dos textos de Eisenman sobre Terragni, Rowe já havia desenvolvido, no final dos anos 50 e início dos 60, os termos para uma interpretação formalista da arquitetura moderna, basicamente através de suas elaboradas leituras de Le Corbusier. A contribuição de Eisenman para esse discurso será suspender a análise formal de base estruturalista, uma aparente e ligeira mudança na ênfase que, enfim, faria ruir o modo como o formalismo americano havia institucionalizado o modernismo, no contexto do pós-guerra. Em outras palavras, Eisenman foi capaz de transformar o discurso desde dentro, ao apropriar o termo "formalismo", desdobrando-o, para compreender a noção mais polêmica de "linguagem" no sentido do formalismo Russo." Este movimento de Eisenman começa a desterrar a estetização da obra de arte única, que acompanhou a versão anglo-americana do formalismo, presente nos trabalhos do New Critics ${ }^{\vee}$, da crítica de Clemente Greenberg e até mesmo em Rowe. De modo geral, o projeto de Eisenman sempre considerou o retorno aos aspectos críticos das vanguardas históricas, aspectos que foram represados, na teoria e na prática, precisamente pela reconstrução formalista depois da guerra. Como Eisenman escreveu num de seus artigos sobre Terragni - indicando a intenção de utilizar estas estratégias como ferramentas descritivas de projeto - "enquanto a análise formal é um método válido para a história da arte, em si mesmo pode se tornar apenas descritivo - um exercício de ginástica intelectual" ${ }^{13}$ Não apenas a história da forma seria reescrita, mas Eisenman iria sujeitar a forma a uma revisão perpétua, através de exaustivas seqüências de operações: transformação, decomposição, inserção, escavação, rotação, inversão, superposição, deslocamentos, dobras, etc. E é o catálogo desses procedimentos que se torna a matéria da própria arquitetura, uma pré-condição disciplinar para uma abordagem diagramática. Através de uma lógica extrema, Eisenman se compromete, alternadamente, com a crítica tanto pelo, como do cálculo (ou matemática), tanto das geometrias ideais de Rowe, como da "adequação da forma"w de Christopher Alexander.

Por volta de 1970, Eisenman distinguiria as práticas de Corbusier e Terragni (e, indiretamente, o 
vro em questão ["The Diagram, and the Becoming Unmotivated of the Sign", in Diagram Diaries, pp.211215], se refere à Semiótica de Peirce de forma diádica, reduzindo suas três categorias a apenas duas: uma indicial e outra que confundiria icônico e simbólico. É preciso ressaltar que Peirce define 0 diagrama como um tipo especial de ícone, um hipoícone: "Formamos na imaginação uma certa representação diagramática, isto é, icônica, um esqueleto tanto quanto possivel. (...) Se for visual, será geométrico (...) ou algébrico (...). Esse diagrama, que foi construído para representar intuitivamente as mesmas relações abstratas expressas nas premissas, é então observado e uma hipótese sugere que há certa relação entre suas partes (...). Para testar isso, várias experimentações são feitas sobre o diagrama, que se modifica de várias maneiras." PEIRCE, Charles Sanders. Collected papers, volume II. Cambridge: Harvard University Press, 1978, parágrafo 778

t. Ver EISENMAN, Peter. Dall'ogetto allá relazionalità: la casa Del Fascio di Terragni, in Casabela, $n^{\circ} 344$, pp. 38-41. Milão: Casabela, 1970; EISENMAN, Peter. From Object to Relationship II: Casa Giuliani Frigerio, in Perspecta 13/14, 1971, pp.36-65.

u. Parece ser fundamental compreender os conceitos do Formalismo Russo para compreender o movimento de Eisenman. O Formalismo Russo foi uma das vertentes do modernismo no início do século XX, desenvolvido a partir de 1914. Um dos manifestos formalistas mais importantes talvez seja o de Victor Chklóvski, A arte como procedimento, em Sur la théorie de la prose, Lausanne: Editions L'Age d'Homme, 1973. Chklóvski afirma que o fazer da arte se sustenta numa base sintática, na construção da linguagem que se processa. A obra deve ser extraída de seu contexto habitual, provocando um estranhamento, dificultando a percepção. Para uma disCussão aprofundada, ver FERRARA, Lucrécia D'Aléssio. A estratégia dos signos, São Paulo: Perspectiva, 1981, pp. 5-7 e ss. e 33-35. formalismo de Rowe do seu próprio), ao incorporar a terminologia da lingüística estrutural de Noam Chomsky ${ }^{*}$. Enquanto a arquitetura de Corbusier permanece comprometida com a criação do significado através da iconografia, da semântica do objeto, Eisenman defende que a obra Terragni está preocupada em revelar a sintaxe da linguagem arquitetônica. Esta mudança representa um distanciamento das preocupações com as qualidades perceptuais-estéticas do objeto, em direção a uma tentativa de demarcar as relações conceituais que estruturam e possibilitam qualquer (e todo) arranjo formal particular. Além disso, considera que a obra de Terragni demarca a relação entre "estrutura de superfície" e "estrutura profunda", através de métodos transformacionais, que Eisenman procura revelar por uma série de diagramas axonométricos e projeções. Aqui é preciso notar que a técnica axonométrica (ou projeção paralela) foi um dos dispositivos das vanguardas históricas recuperados por esta geração, especialmente por Eisenman e Hejduk. ${ }^{14} \mathrm{Em}$ contraste com outro modelo dominante de desenho tridimensional, a projeção central ou perspectiva do humanismo da Renascença, a axonométrica favorece a autonomia do objeto ao conter informação objetiva ou mensurável, ao invés da distorção criada por um ponto de fuga orientado para o sujeito observador. Onde a análise de Rowe se desenrola separadamente em plantas e elevações, a axonométrica apresenta planta, corte e elevação, mais uma vez articulando vertical e horizontal um ato que foi notado anteriormente, por exemplo, como uma das aspirações de Venturi no Billdingboard. Além do mais, ao contrário das "linhas reguladoras" de Corbusier - descrições geométricas se inserem aos seus objetos depois de sua construção - o dispositivo tridimensional da axonométrica permite que análise e objeto se tornem congruentes.

Através de seus diagramas axonométricos, Eisenman argumenta que Terragni desenvolve uma ambigüidade conceitual ao superpor duas concepções de espaço - aditiva/estratificada e subtrativa/volumétrica - nenhuma das duas dominantes, mas as duas oscilando entre si indefinidamente. O efeito dessa dupla leitura não é apenas estético, mas opera como um índice de uma estrutura profunda: isto é, investigar e tornar aparente as possibilidades e limitações da linguagem da arquitetura em si. A atenção de Eisenman à forma, então, pode ser vista como um meio para desenvolver esse método transformacional como ferramenta analítica e descritiva de projeto. É uma tentativa de prover o programa das vanguardas históricas de um movimento temporal e espacial que impediria qualquer contemplação estática do objeto de arte. Nesse sentido, o "desenho do modernismo" de Eisenman, os suplementos diagramáticos de sua escritura (graffitı) americana, anuncia o aniquilamento do objeto arquitetônico e o princípio de seu processo de desaparecimento.

Contemporaneamente ao trabalho histórico-crítico sobre Terragni, Eisenman começava uma série de projetos em que desenvolveria muitas das estratégias transformacionais que estava "descobrindo" em suas análises do cânone moderno. Os diagramas transformacionais, numerados seriadamente, das Casas I e II, assim como os diagramas retrospectivos criados para a obra de Terragni, sugerem que as estruturas "finais" construídas são apenas signos indiciais que apontam para um processo mais amplo, do qual são apenas uma parte. Não se trata apenas de movimento gerado através de séries de contextos individuais - o processo todo mais se parece com uma operação cinemática, com sua montagem de quadros congelados (stills) - mas, dada a natureza da projeção axonométrica (exagerada aqui por sua construção transparente, em wireframe), há também uma oscilação constante e um movimento reversível contido em cada diagrama: o observador está ora dentro, ora fora; agora debaixo, agora sobre. Retomando o novo papel híbrido do arquitetocrítico, este efeito sugere a coincidência e a cumplicidade entre a condição formal "interna" e a construção "externa" da subjetividade. Somada ao processo transformacional de apagamento do objeto, esse procedimento começa a destituir o sujeito (como criador e usuário), uma vez que o índice arquitetural que resta não depende mais da iconografia ou das funções do homem. Isto tem relação com o argumento de Eisenman de que a arquitetura moderna nunca foi suficientemente modernista devido ao funcionalismo, que ela remonta a nada mais que "uma fase tardia do humanismo." 15 Deslocando a arquitetura de uma base formal para a estruturalista, ou de uma base icônica ou semântica para uma base indicial ou 
v. A crítica literária norte-americana e inglesa, entre 1920 e 1960, considerava que uma obra deveria ser lida sem a utilização de qualquer outra fonte externa senão a obra em si. Formalista, a teoria defendia a autonomia da obra que, por mais complexa que fosse, formaria uma unidade.

w. Tradução de Goodness of fit, termo bastante utilizado em algumas ciências exatas que designa a qualidade da forma para se conformar a certos estados, em determinados contextos, visando determinadas soluções.

$x$. Chomsky, lingüista norteamericano que revelou possibilidades formais para a compreensão da língua não a partir do significado, da semântica, mas sim das relações formais das estruturas sintáticas. Ver CHOMSKY, Noam. Syntactic structures. Haia, Paris: Mouton, 1957.

y. Ver EISENMAN, Peter. Aspects of modernism: Maison Dom-ino and the selfreferential sign, in Oppositions $n^{\circ}$ 15/16, Nova lorque: The Institute for the Architecture and Urban Studies, 1979, pp. 119-128. sintática, seria possível, finalmente, à arquitetura, alcançar os pressupostos das vanguardas modernistas, uma consideração que suspende a centralidade clássico-humanista do sujeito e propõe a arquitetura como "a mediação abstrata entre sistemas de signos pré-existentes," ${ }^{16}$ ou, como ele escreveria mais tarde sobre o Dominó de Corbusier, como um "signo auto-referencial." y

Ao deslocar o autor-sujeito (e, por fim, o objeto estático), as primeiras arquiteturas de "papel cartão", ou conceituais, de Eisenman foram projetadas "para mudar o foco primário dos aspectos sensuais dos objetos, para os aspectos universais do objeto" e "para investigar a natureza do que tem sido chamado de formal universal, inerente a toda forma e a todo construto formal." 17 As investigações de Eisenman exigiam, portanto, uma forma inicial genérica ou universal, que ele, com freqüência, localizava no cubo, a caixa neutra que era tipicamente designada como um diagrama de nove-quadrados (e desse modo, menos neutra). Diferente das premissas do problema dos nove-quadrados articulado em Austin (que prosseguiu na pesquisa pessoal de Hejduk sobre o tema em suas sete Texas Houses, de 1954 a 1963), Eisenman não privilegia o "espaço" (da variedade de van Doesburg) como elemento dinâmico e dominante a ser lido, em contraposição a estática da estrutura (do tipo Dominó). Ao contrário, na Casa II (1969), por exemplo, são registrados múltiplos indícios do sistema de colunas e de paredes, traços que fornecem os efeitos espaciais gerais do projeto. Assim, a ativação do esqueleto ou malha estrutural engendra o evento espacial do objeto - um tipo de objetivação da estrutura, similar a associação de Eisenman da arquitetura, mais com o estudo da linguagem do que com a linguagem em si. Essa tática vai reaparecer em trabalhos posteriores onde há uma figura-devir da estrutura (por exemplo, o Aronoff Center) ou um maneirismo sobre a malha que, por fim, se manifestará a si própria através da organização da dobra (por exemplo, no Rebstockpark).

Na Casa VI (1973-76), a clássica organização dos nove-quadrados, utilizada inicialmente nas primeiras Casas, se transforma num quatro-quadrados, mais modernista, uma organização que se tornará mais evidente nas Casas subseqüentes. Ao longo da série completa de projetos, contudo, Eisenman trabalha na constrição do diagrama moderno, apenas para desfazer seus princípios e valores fundamentais, subvertendo a lógica clássicohumanista dos nove-quadrados. Em outras palavras, a concepção moderno-maneirista da forma em Rowe como relação entre espaço e estrutura, é agora compreendida como o resultado mais provisório do par tempo e movimento. Especificamente na Casa VI, as fachadas não são a informação vertical básica para a leitura de transparências fenomenais, mas são empurradas para o interior como se a periferia agora cruzasse o centro da estrutura. Flutuando acima do chão, com nenhuma entrada visível, é uma Casa que, para todos os propósitos práticos, poderia estar de cabeça para baixo ou do avesso. Aqui, o valor da frontalidade, que acompanhou as associações pictóricas achatadas entre plantas e elevações nos ensaios e análises de Rowe e Slutzky, é corroído por deslocamentos cinemáticos e temporais fornecidos pela axonometria. Com Eisenman, os nove-quadrados não são mais pensados pela lógica da pintura, mas pela do cinema e é esta concepção que permite a existência simultânea da experiência e da representação.

"A Casa VI...existe ao mesmo tempo como objeto e como um tipo de manifestação cinemática do processo transformacional, em que os quadros da idéia de um filme se tornando perceptíveis independentemente na Casa. Assim, o objeto não se torna apenas o resultado final de sua própria história gerativa mas retém sua história, servindo como seu completo arquivo, processo e produto se tornando intercambiáveis." 18

Descritas através de arranjos seqüenciais de diagramas axonométricos, as Casas de Eisenman são concebidas como parte de um movimento cinemático, quadros (stills) arbitrários traduzidos em três dimensões, em séries potencialmente infinitas. Entendido como um passo da ambigüidade rumo à indecidibilidade ou das oposições binárias às micro-multiplicidades, os trabalhos mais recentes de Eisenman insistem sobre uma superfície de leitura que questiona a possibilidade de materialização do significado e parece operar apenas como uma série sem fim de conjunções - e, e, e...uma coisa depois da outra. Há aqui uma repetição literal (como o repúdio a Bauhaus, evitado por Rowe, ou a rejeição 
z. Para discussões mais aprofundadas sobre o conceito de maquínico em arquitetura, ver: ZAERA-POLO, Alejandro. Una conversación con Peter Eisenman, in El Croquis $n^{\circ} 83$, pp. 6-20. Madrid: El Croquis Editorial, 1997; LACOMBE, Octavio. Diagramas Digitais: pensamento e gênese da arquitetura mediada por tecnologias numéricas, Tese de Doutorado, São Paulo: FAUUSP, 2006.

aa. L'Année dernière à Marienbad, filme de 1961, direção de Alain Resnais e argumento/roteiro de RobbeGrillet, apresenta uma estrutura narrativa complexa, com tempos e espaços sobrepostos, múltiplos, recorrentes.

bb. Matemático francês, especialista em topologia, René Thom elaborou a Teoria das Catástrofes que consiste em considerar que uma forma pode sofrer perturbações e se modificar, atravessando um limiar de catástrofe que altera sua organização. Segundo Charles Jencks, em The architecture of the jumping universe, Londres: Academy Editions, 1997, dois dos sete tipos de catástrofes de Thom são dobras. Sobre a dobra em arquitetura, ver DELEUZE, Gilles. A Dobra: Leibniz e o Barroco, tradução Luiz Orlandi. Campinas: Papirus, 1991; AD - Architectural Design, Folding in architecture, volume $63, n^{\circ} 3$ / 4, Londres, Academy Editions, 1993 do crítico de arte Michael Fried ao minimalismo) que aposta na chance da emergência de outra condição, através do processo de iteração maquínico ${ }^{z}$ (num sentido amplamente bio-mecânico). De fato, os projetos que se desenvolveram desde o Wexner Center não podem ser discutidos propriamente como "obras" ou "objetos" ou "formas" ou mesmo "estruturas" - todos termos excessivamente estéticos ou técnicos, muito demarcados e definidos. Ao contrário, eles apenas parecem ser "coisas", com toda a informalidade e as possibilidades transformativas do monstruoso e do grotesco que o termo implica. Essas recentes "coisas" vermerizomas parecem frustrar e derrubar as análises formais, indicando uma transição de um claro estruturalismo do primeiro Roland Barthes para o materialismo de base de George Bataille, teórico do excesso. Em seu quase-dicionário, na entrada para o termo informal Bataille escreve que "o que isto designa não tem substância e vê a si mesmo esmagado por toda a parte, como uma aranha ou uma lesma." 19 Nos projetos pós-vermiformes, desde o Columbus Convention Center, a investigação teórica da forma se moveu francamente para abarcar o informe, ou uma condição a que Eisenman e seus colegas se referiam como "forma débil".

Para Eisenman, a arquitetura - ao contrário da escrita - deve lutar contra sua presença literal, que é tradicionalmente reforçada pelos ícones da "forma forte". Para articular essa condição não dialética entre presença e ausência, Eisenman aplica o termo "presentidade" como uma possibilidade para uma prática "débil", o risco (casualidade) da arquitetura como evento. Enquanto ele e Michael Fried se opõem à presença literal, o uso do termo por Eisenman deve ser diferenciado do uso que faz Fried do conceito. Para Fried, "presentidade" implica um objeto dotado de profundidade e plenitude, qualidades instantaneamente auto-evidentes que, assim, induzem à crença e à convicção imediatas. Por outro lado, o uso de Eisenman tem mais em comum com a perpétua re-contextualização e a condição temporal ilimitada do minimalismo, ao qual Fried argumenta contra. De fato, o minimalismo opera de modo diagramático, uma vez que instiga e corrói uma oposição chave do formalismo modernista - especificamente, aquela entre pintura e escultura - como se pode ver emergindo em resposta a evolução dos dois meios (o que, é claro, seria impossível do ponto de vista do axioma modernista a favor da especificidade dos meios e pela manutenção de suas fronteiras). Finalmente, onde a "presentidade" de Fried se suporta sobre uma condição de atemporalidade, Eisenman está envolvido com o estado de "singularidade" - isto é, um momento específico numa fase de transição, em que diversas forças, atuando sobre a matéria, induzem à emergência de peculiaridades imprevistas.

Uma primeira forma dessa singularidade pode ser vislumbrada num projeto como Rebstockpark que propõe um empreendimento de 200.000 metros quadrados de escritórios e moradias em Frankfurt (1991), um análogo urbano da cronografia cinemática do filme 'O ano passado em Marienbad'aa de Alan Resnais e Robbe-Grillet. Aqui, a condição entre da "presentidade" requer levar em consideração o arbitrário, o acidental. Mais do que a narrativa (tempo-forte), sucessão de presentes (como, talvez, representado no Wexner Center), esses eventos-dobra guardam "picos do presente", onde há uma coexistência de um presente do futuro, de um presente do presente e de um presente do passado. Descrevendo a imagem-tempo encontrada na obra de Robbe-Grillet, Deleuze escreve:

“Um acidente está para acontecer, acontece, aconteceu; mas igualmente, será ao mesmo tempo que isto acontecerá, já terá acontecido e estará acontecendo; assim, antes de acontecer, não aconteceu e, acontecendo, não acontecerá...etc." 20

Na indecidibilidade entre se há contração do sítio do Rebstock para absorver a rede exterior neutra ou se é no processo de expansão para desdobrar sua informação por uma área maior, o projeto oferece uma versão urbana de vislumbres de "presentidade", similar às visões literárias e cinemáticas de Robbe-Grillet e aos modelos matemáticos de René Thom ${ }^{\text {bb }}$. Em episódios, tanto de larga, como de pequena escala, há uma multiplicação de tempos: já dobrado, dobrando, ainda não dobrado. Começando em Rebstock - e prosseguindo até a Igreja do ano 2000, a Biblioteca de L'IHUEl, a Casa Virtual e o IIT Campus Center a "imagem-movimento" dos primeiros projetos (onde o diagrama estava limitado a um desdobramento linear do tempo, uma recuperação da genealogia da obra, como se o tempo tivesse 
cc. A partir da segunda metade do século XIX, Eadweard Muybridge [1830-1904], fotógrafo inglês, foi pioneiro da investigação e da experimentação para a representação do movimento. Fez uma série de experimentos chamados cronofotografias ou decomposição do movimento, captação de imagens do movimento por múltiplas câmeras. uma variação-dependente do movimento, como em Muybridgecc), foi trocada por uma "imagemtempo". Curiosamente, como campo de condições intensificadas mais do que ideais ou generalidades distorcidas, estes projetos se assemelham mais ao diagrama degenerado de Rowe, o "programa sem planta", do que com a "planta sem programa."

Diferenciando "o evento" de seqüência narrativa organizada por um enredo, John Rajchman sustenta que este é "um momento de erosão, colapso, questionamento ou problematização das suposições do cenário em que o drama pode se desenrolar, proporcionando a chance ou a possibilidade de outra cena diferente." 21 Eventos são tão acidentais quanto o fato de sua ocorrência engendrar a realização do que é considerado necessário e natural. O projeto do Rebstockpark promove um "evento" arquitetônico, uma manifestação do tempo fraco, com o alcance de trazer a tona uma reestruturação ativa da tipologia, do contexto, das funções e da arqueologia. Nem historicista nem progressista - e, portanto, em nenhuma categoria do possível - esse tipo de tempo pode ser pensado como "virtual", o que é simplesmente uma impossibilidade histórica, nem lógica, nem necessária. Como investigação do virtual, a proposta do Rebstock é uma experimentação e não uma interpretação. E é através dessa qualidade experimental - "presentidade" como finalidade ou singularidade - que o esquema projeta uma "realidade virtual". É desse ponto que pode ser possível iniciar uma avaliação da dobra nas obras mais recentes de Eisenman, uma vez que a dobra é exatamente um mapa do evento, uma descrição geométrica do inesperado, um diagrama do virtual.

Certamente, na trajetória que vai do Billdingboard de Venturi às manipulações dissimuladas das axonométricas de Eisenman, evidenciadas na Casa $X$ e na Casa Fin d'Ou T Hou S, a dobra é talvez o dispositivo mais avançado e econômico para articular a vertical e a horizontal, revertendo o dentro e o fora. Como um emblema das atividades híbridas dos arquitetos-críticos, (e seu privilegiado métier de papel), a dobra é simplesmente a distância mais curta entre duas disciplinas, dois discursos incomensuráveis. Como figura, a dobra indicia, imediatamente, um processo, uma ação. Diferente de uma transformação secundária ou decomposição de uma forma ideal ou genérica como um cubo, a dobra é, a uma só vez, a coisa e seu processo. É a operação de dobrar que gera a forma, antes do que, a coisa, simplesmente, não existia. Nesse sentido, a dobra não é uma mera distorção de ou oposição a uma forma tipo definida (por exemplo, como na transformação de um cubo), mas revela a repetição que produz algo inteiramente novo, uma organização emergente que, em suas atualizações mais bem sucedidas, não é simples rejeitar como ideal degradado ou desprezado.

Para Eisenman, então, a instrumentalização da dobra - a tradução dessa figura operacional em uma técnica disponível para o repertório da produção arquitetural - resolveu muitos dos dilemas (e incompatibilidades) internos das duas primeiras fases de seu trabalho. Em outras palavras, enquanto a série de Casas se desenvolveu a partir de manipulações da estrutura interna, os projetos arqueológicos foram engendrados pelas contingências externas do contexto. Além de prover um sentido para agenciar as relações entre a armadura da estrutura interna e a malha urbana externa, a dobra habilita o desenvolvimento de efeitos figurativos (que foram evitados no processo das (asas), assim como seções [cortes] complexas (que são encobertas pela importância da planta na escala do projeto arqueológico). Além disso, uma vez que o informenão é simples negação da forma, mas sua sustentação e subversão mais complexa, a forma permite abrandar as organizações homogêneas ou hierárquicas sem abandonar completamente o rigor e a disciplina geométrica. Posto que a dobra existe como um aspecto alternativo (ou topológico) da matemática, nesse sentido, promete suplantar não só o formalismo da matemática clássica de Rowe, mas também a crença na funcionalidade eficiente da versão cibernética de Alexander. No movimento desde as formas estruturalistas de concussão textual para as singularidades da dobra, Eisenman forneceu um programa eficiente para o duplo projeto de desmantelar o objeto clássico-modernista e o sujeito liberal-humanista. Enquanto a série de Casas enfatizou o processo como meio para desterrar o designer de sua posição de agente autoral, os projetos arqueológicos (de Cannaregio a Wexner) procuram por novas definições de contexto que 
iriam desestabilizar a identidade estática do lugar. Como continuação dessas reconfigurações de processo e contexto, os projetos dobrados trouxeram uma preocupação com o corte, como crítica a decidibilidade planimétrica da tipologia, que tende à contenção dos objetos através da lógica limitada da extrusão.

Nas duas décadas seguintes à sua introdução em 1957, o diagrama dos nove-quadrados serviu como introdução formal da disciplina para si mesma, estabelecendo o discurso do espaço e da estrutura e provendo uma série de conjuntos de soluções através das pesquisas adjacentes de Hejduk, Eisenman e outros. Depois de 1974, em contextos acadêmicos e profissionais, contudo, essa epistemologia do espaço foi rapidamente substituída por um forte pragmatismo, tanto que o alto-moderno diagrama dos nove-quadrados que serviu aos propósitos formais da primeira geração da crítica semiótica - foi suplantado por um tipo bastante diverso de diagrama, um diagrama que tem sua forma histórica na discussão do Panopticismo de Michel Foucault e Deleuze. Para esses pensadores, o Panopticismo existe como diagrama das modernas sociedades disciplinares, que abriga múltiplos tipos de instituições (prisões, hospitais, escolas, fábricas, quartéis, etc.) e uma que pode ser caracterizada, mais abstratamente, como a tentativa "de impor uma conduta particular sobre uma multiplicidade humana particular."22 Desde Piranesidd as prisões não proviam tal oportunidade para especulações arquiteturais extremas e, logo depois do projeto "Exodus" de Rem Koolhas, ele e seu Office for Metropolitan Architecture (OMA) tiveram a chance de engajar diretamente o diagrama panóptico num estudo para a renovação da Prisão Kopel, em Arnheim (1979-81), construída originalmente segundo os princípios de Jeremy Bentham de 1787. Mais que uma tentativa de formalizar qualquer visão corrente (logo tornada obsoleta) do gerenciamento de prisões, OMA propõe num sentido arranjar vários diagramas de poder:

"Se a arquitetura de prisões não pode mais pretender hoje em dia materializar um 'ideal', pode readquirir credibilidade pela introdução do tema da revisão como razão de ser. Uma arquitetura moderna de prisão consistiria numa arqueologia prospectiva, projetando constantemente novas camadas de 'civilização' sobre velhos sistemas de supervisão. A essência das modificações refletiria na infinita evolução dos sistemas disciplinares" 23

Portanto, a importância da lição do panopticismo não é simplesmente para ser apropriada como imagem para um novo sistema organizacional, mas de modo mais geral, para compreender (e configurar) a sociedade como uma entidade plástica, suscetível a múltiplos (virtuais) diagramas e possibilidades de arranjo.

Identificada essa mudança conotativa na maneira pela qual o diagrama foi instrumentalizado na arquitetura, ao longo das últimas décadas, não se deve tomar, contudo, equivocadamente, esta transição por algumas oposições essenciais. Apesar das colocações de vários críticos e arquitetos, Koolhaas e Eisenman, por exemplo, têm muito mais em comum do que o primeiro tem com Jon Jerde ou o segundo com Frank Gehry. Trabalhar diagramaticamente - não confundir com apenas trabalhar com diagramas - implica uma orientação particular, que considera a uma só vez projetos sociais e disciplinares. E cumpre essa possibilidade não pela representação de uma condição particular, mas subvertendo oposições e hierarquias dominantes comumente constitutivas do discurso. O trabalho diagramático, então (e isso inclui os projetos de Eisenman e Koolhaas), não pode ser levado em conta pela reaplicação, crítica ou cúmplice, das categorias convencionais do formal e do funcional. Ele opera como alternativa às tentativas anteriores de colocar "arquitetura" entre aspas (o reparador ou afirmativo signo do pós-modernismo) ou fixando um sinal "me bate" nas costas (o gesto aparentemente crítico do primeiro deconstrutivismo, agora institucionalizado em alguns programas de doutorado por toda parte). O trabalho diagramático é projetivo, pois abre novos (ou mais acuradamente, "virtuais") territórios para a prática, bastante próximo do modo como Deleuze descreve a pintura diagramática de Francis Bacon, como que ultrapassando o viés óptico da arte abstrata, assim como a gestualidade manual do action painting:

"Um Saara, uma pele de rinoceronte, isto é o diagrama, subitamente estirado. É como uma catástrofe acontecendo inesperadamente na tela, 
dentro da informação figurativa ou probabilística. É como a emergência de um outro mundo.

...O diagrama é a possibilidade do fato - não é o fato em si." 24

Esta "emergência de um outro mundo" é precisamente aquilo que o diagramático diagrama. Isso pode explicar por que, quase que sozinhos entre suas respectivas gerações, Eisenman e Koolhaas - professores e críticos assim como designers persistentemente e curiosamente evitaram o projeto (design) (e, junto a isso, a trajetória pós-renascentista da arquitetura obcecada com o desenho, a representação e a composição). Essa alternativa diagramática pode ser encontrada inicialmente na autonomia do processo de Eisenman e, mais recentemente, nas pesquisas estatísticas de Koolhaas: tentativas complementares de suplantar o projeto com o diagrama, de chegar à forma sem beleza e a função sem eficiência. Uma prática diagramática (flutuar em torno dos obstáculos sem a nada resistir) - oposta à visão tectônica da arquitetura como signo legível da construção (que pretende preservar seu estatuto potencial como comodidade e especulação cultural) - multiplica processos significantes (tecnológicos, assim como lingüísticos) na plenitude da matéria, reconhecendo signos como cúmplices na construção de máquinas sociais específicas. O papel do arquiteto, nesse modelo, é dissipado, uma vez que se torna um organizador e canalizador de informação, não se limitando ao decididamente vertical - o controle e a resistência à gravidade, o cálculo de estatísticas e cargas -, "forças" horizontais e não específicas emergem (econômico, político, cultural, local e global). E é pelo significado do diagrama que esses novos problemas e atividades - junto com suas diversas ecologias e multiplicidades - podem se tornar visíveis e relacionados. Contra um dos mais comuns e pueris adjetivos ao legado de Eisenman e Koolhaas, é importante evitar o confinamento da abordagem diagramática na arquitetura à expressão de supostos imperativos bio-matemáticos, ou a inevitabilidades econômicas, e compreender a arquitetura mais como um campo discursivomaterial de plasticidade político-cultural. Fazer de outro modo seria retornar às opções diagramáticas inadequadas delineadas por Rowe (em termos de "verdade" analítica ou formal) e Alexander ("verdade" operacional ou sintética). E seria também perder as oportunidades virtuais instigadas pelos projetos-pesquisa que Eisenman tem conduzido pelos últimos trinta anos, simplesmente (e brutamente) colecionados aqui como catálogo de procedimentos ("funções" ou "tensores"), uma arquitetura que veio para desviar de uma geometria a priori, assim como da acomodação social, em favor das "possibilidades de fato" de Bacon.

\section{Notas do autor}

1 Christopher Alexander, Notes on the Synthesis of Form, Cambridge: Harvard University Press, 1964. Para mais sobre o 'debate' entre Eisenman e Alexander, ver "Contrasting Concepts of Harmony in Architecture", Lotus International 40, 1983.

[n.t] Há uma tradução em língua espanhola: ALEXANDER, Christopher. Ensayo sobre la síntesis de la forma, tradução Enrique Revol. Buenos Aires: Ediciones Infinito, 1969.

2 Reyner Banham, 'A Black Box', in A critic Writes, Berkeley: University of California Press, 1996, p.298.

${ }^{3}$ Colin Rowe, 'Program versus Paradigm: Otherwise Casual Notes on the Pragmatic', in As I Was Saying, vol.2, Cambridge: MIT Press, 1996, p.10

${ }^{4}$ Depois, esta transformação se tornará mais evidente via as estratégias arquiteturais da 'dobra', procedimentos que em parte continuam as complicações entre horizontal e vertical ao exagerar a desmaterialização de 'arquiteturas de papel'

${ }^{5}$ Esta visão da repetição segue as considerações de Deleuze sobre os dois meios para conceber a diferença: "Só aquilo que é igual se parece" e "Só diferenças são parecidas". Na primeira versão, a diferença só pode derivar de uma identidade ou autonomia a priori (por exemplo, o modo como cada pé de sapato são diferentes por sua relação com uma identidade anterior, o par) enquanto na segunda versão as diferenças operam horizontalmente ao invés de verticalmente, num estado de se tornar idêntico (por exemplo, o encontro surreal da maquina de costuras e do guarda-chuvas). Veja Lógica do sentido (indicar edição) e Diferença e repetição (indicar edição).

${ }^{6}$ Gilles Deleuze, "Platô and the Simulacrum", October 27 (Winter, 1983), p.36.

7 Colin Rowe, "The Mathematics of the Ideal Villa", in The Mathematics of the Ideal Villa and Other Essays, (Cambridge: MIT Press, 1976), pp.15-16.

[n.t.] Há uma edição em espanhol: Rowe, Colin. Manyerismo y Arquitectura Moderna y Otros Ensayos, Barcelona: Editorial Gustavo Gili, 2000.

${ }^{8}$ Colin Rowe, Five Architects (New York: Oxford University Press, 1972), p.8.

${ }^{9}$ Rowe, "The Mathematics of the Ideal Villa", p.16.

${ }^{10}$ Para uma história detalhada desse programa do ponto de vista de um participante, ver Alexander Caragonne, Texas Ranger: Notes from an Architectural Underground (Cambridge: MIT Press, 1995).

${ }^{11}$ Essa questão de ensino de projeto teve paralelo com a obra particular de Hejduk, as sete "Texas Houses", uma série iniciada em 1954 e dedicada posteriormente a Rowe e Slutzky. Ver John Hejduk, Mask of Medusa (New York: Rizzoli, 1985), p.197 e pp.222-237.

12 Rowe, Five Architects, p.7.

${ }^{13}$ Peter Eisenman, "From Object to Relationship II: Giuseppe Terragni's Casa Giuliano Frigerio", Perspecta 13/14 (1971), p.41.

${ }_{14}$ Mesmo que largamente adotada pelos modernistas da vanguarda dos anos 20 e 30, as projeções axonométricas virtualmen- 
te desapareceram como recurso gráfico até o final dos anos 50 , tendo sido rejeitadas por aqueles que procuravam mimetizar mídias mais estáticas e pictóricas na reconstrução do modernismo no pós-guerra. Rowe e Johnson, por exemplo, foram explicitamente contra os efeitos de "flutuação", "rotação" e "de diagonal" associados a isométricas e axonométricas. Será sugerido, posteriormente, que Eisenman resgata a axonométrica não apenas como representação gráfica, mas como ferramenta de projeto, usando suas características como dispositivo gerativo. Para um debate histórico sobre axonométrica, ver Yve-Alain Bois, "El Lissitzky: Radical Reversibility", Art in America(Abril 1988), pp.160-80 and "Metamorphosis of Axonometry", Daidalos I (1981), pp.40-58, assim como Robin Evans, "Architectural Projection", Architecture and its Image, Eds. Eve Blau and Edward Kaufman, (Montreal: Canadian Centre for Architecture, 1989), pp.19-35

${ }^{15}$ Peter Eisenman, "Post-Functionalism", Oppositions 6 (Fall 1976), p. ii (unnumbered).

n.t] Há uma recente versão para o português, O Pós-funcionalismo, em NESBITT, Kate (org.), Uma nova agenda para a arquitetura: antologia teórica (1965-1995), tradução Vera Pereira, São Paulo: Cosac \& Naify, 2006, pp. 95-101.

${ }^{16}$ Eisenman, "Post-Functionalism", p. iii (unnumbered).

17 Peter Eisenman, "Notes on Conceptual Architetcture", Casabella 359/360 (1971), p.55. Para uma formulação anterior, porém similar, ver "Towards an Understanding of Form in Architetcture" Architectural Design, (Outubro, 1963), pp.457-458.

${ }^{18}$ Peter Eisenman, "Misreading Peter Eisenman", House of Cards, (New York: Oxford University Press, 1987), pp.178 e 181. Ver também Peter Eisenman, "House VI", Progressive Architecture (Junho, 1977), p.59: "o Projeto da Casa VI é simbiotico com sua realidade: a casa não é um objeto no sentido tradicional - ou seja, o resultado final de um processo - mas, mais acuradamente, o registro de um processo. A casa, como o conjunto de transformações diagramáticas no qual seu projeto esta baseado, é uma série de quadros congelados de filme compostos no tempo e no espaço." Para mais sobre a idéia de arquitetura como documento, ver a discussão similar de Venturi sobre o muro em Complexidade e Contradição em Arquitetura.

19 Georges Bataille, "Formless", in Visions of Excess: Selected Writings, 1927-1939(Minneapolis: University of Minnesota Press, 1985), p.31.

${ }^{20}$ Gilles Deleuze, Cinema 2: The Time-Image (Minneapolis: University of Minnesota Press, 1989), p.100.

${ }^{21}$ John Rajchman, Philosophical Events: Essays of the 80's (New York: Columbia University Press, 1991), p.viii.

22 Gilles Deleuze, Foucault (Minneapolis: University of Minnesota Press, 1988), p.34. Para a discussão de Foucault, ver Discipline and Punish (New York: Pantheon, 1977), originally published as Surveiller et punir (Paris: Gallimard, 1975), e "The Eye of Power", in Power/Knowledge: Selected Interviews and Other Writings, 1972-1977, Ed. Colin Gordon (New York, Pantheon, 1980)

[n.t] Sobre o Panopticismo em português, ver FOUCAULT, Michel. Vigiar e punir, tradução Raquel Ramalhete. Petrópolis: Vozes, 1987.

${ }^{23}$ Rem Koolhaas, "Revision", in S,M, L, XL (New York: Monacelli Press, 1996), p.241.

${ }^{24}$ Gilles Deleuze, "The Diagram", in The Deleuze Reader, Constantin V. Boundas, ed. (New York: Columbia University Press, 1993), pp.194,199. 